\title{
Estudos sociais para crianças numa democracia: prescrições didáticas para o ensino de história sob o prisma norte- americano
}

\author{
Social studies for children in a democracy: didactic prescriptions on \\ History teaching under the American approach
}

Elisiane da Silva Soares ${ }^{1}$

Eliana Rela ${ }^{2}$

RESUMO

Este texto analisa o manual Estudos Sociais para crianças numa democracia, com enfoque em sua materialidade e conteúdo. A obra foi originalmente publicada em 1956, por John U. Michaelis, Professor da Escola de Educação da Universidade de Berkeley, Califórnia. No Brasil, a disciplina de Estudos Sociais tornou-se obrigatória no Ensino Básico e no Ensino Superior a partir de 1967. Em 1969, foi, então, implantado o curso de Estudos Sociais na UCS, que utiliza o manual de Michaelis como referência. O livro apresenta prescrições aos professores que desejam "melhorar a educação social das crianças" e seu tema central é a defesa de que "os valores e o comportamento democráticos devem impregnar todas as fases do programa de estudos sociais". A bibliografia desta análise inclui Goodson, Saviani e Bittencourt, além de fontes referentes à implantação do curso de Estudos Sociais na UCS. O objetivo desta discussão é analisar o manual para além do seu conteúdo escrito, abordando, também, a comunicação possibilitada por seus elementos visuais. Evidencia-se a importância de leituras como esta por possibilitar que o material deixe de ser apenas um recurso pedagógico e didático, e passe a ser, também, um discurso sobre ensino de História, datado e contextualizado.

Palavras-chave: História do Ensino de História. História da Educação. Formação de Professores. Cultura Escolar. Prescrições docentes.

\section{ABSTRACT}

This paper aims to discuss the guidebook Social studies for children in a democracy, focusing not only on its content, but also on its materialness. It was written in 1956 by the professor of the UC Berkeley School of Education John U. Michaelis. In Brazil, Social Studies became a mandatory subject for primary and secondary school, and at university, in early 1967. In 1969, the Universidade de Caxias do Sul (UCS) started offering Social Studies as a new graduation course which relied on Michaelis' guidebook as part of its bibliography. Said material is a guide for teachers to "improve children's social education" and its main idea is that "the values and the

1 Mestranda do PPGHIS/UCS. Linha de Pesquisa: Ensino de História e Linguagens. E-mail: essoares1@ucs.br

2 Doutora em Informática na Educação pela UFRGS. Docente do corpo permanente PPGHIS/UCS e PPGEDU/UCS. E-mail: erela@ucs.br 
democratic behavior must pervade all phases of the social studies program". Goodson, Saviani and Bittencourt were taken as reference for this work, and so were materials related to the forthcoming 1969 social studies program at UCS. The purpose is to understand the guidebook beyond its written content, that is, to comprehend also the communication it enables by visual elements. That is therefore a way of considering the guidebook in addition to its pedagogic and didactic potential, and making it a dated and contextualized discourse about teaching and History.

Keywords: History of History Teaching. History of Education. Teacher Training. School Culture. Teaching prescriptions.

\section{O Ensino de História e a Importação de Modelos Educacionais}

O século XIX marcou o importante momento em que a História passa a ser constituída como disciplina escolar. A França serviu de cenário para esse evento, que se desenvolveu em meio a debates e movimentos de distanciamento da religiosidade predominante, estimulando uma visão nacionalista. A mudança propiciava a consolidação dos Estados Nacionais no despontar do modernismo. Em meio a enfrentamentos entre humanistas e cientificistas, a História escolar "desempenhava o papel ora de formadora moral, ora de formadora do cidadão político, no momento em que o tema da 'universalidade' se defrontava com o ‘nacionalismo'” (BITTENCOURT, 1993, p. 194).

A História Sagrada, com base religiosa, que por séculos predominou na Europa, considerava que o regimento da Humanidade se dava através da vontade de Deus, da providência divina com intuito de exortar moralmente os indivíduos. A influência dos pensamentos iluminista e marxista, advinda no século XIX, promoveu a negação dessas ideias e mudou, então, os rumos da História, que, pouco a pouco, deixava de se debruçar apenas em questões filosóficas e teológicas, para dar lugar ao antropocentrismo, que se fortalecia nessas transformações.

No Brasil, a História enquanto disciplina escolar foi instaurada entre o final do período imperial e o início da República, apresentando suas intenções e necessidades sociais e políticas e, tendo o dever de se fazer presente nas instituições de ensino elementares e de nível médio. Bittencourt (1993) afirma que, em 1827, as propostas curriculares que os legisladores pretendiam desenvolver previam que os docentes necessitavam ir além da leitura e escrita e do estudo dos números: o ensino deveria se esforçar em fortalecer a moral religiosa conforme a doutrina do Catolicismo, além da compreensão acerca da História do Brasil e da Constituição do Império.

Baseado no modelo francês, deveras positivista, o ensino brasileiro da época reservava-se à memorização de datas e nomes, enaltecendo os heróis nacionais através de 
seus atos, com objetivo de desenvolver o sentimento de nacionalismo na sociedade. Esse é um momento em que "heróis profanos confundiam-se com heróis sagrados" (BITTENCOURT, 1993, p. 220).

Dentre os movimentos de influência atuantes no período regencial que sucedeu a Independência, em meio a um projeto civilizatório superior ao período Imperial, Nadai (1993) cita, por exemplo, o "pensamento neoliberal francês" e seu importante papel na fundação do Colégio Pedro II, em dezembro de 1837 no Rio de Janeiro, que, no ano seguinte, através de seu regulamento, estabelecia a introdução do ensino de História nos currículos a partir da sexta série. Nesse cenário, identifica-se, também, a fundação do Instituto Histórico Geográfico Brasileiro (IHGB), o qual, afirma Reis (2007, p. 25), até por volta de 1933 "exercerá uma grande influência e será o único centro de estudos históricos do Brasil" e do Arquivo Público do Império, hoje Arquivo Nacional.

Entretanto, e por consequência, ainda que ideais de nacionalismo guiassem a transformação do ensino, os princípios que o caracterizavam eram nutridos por valores europeus. Amparados no positivismo, assumiam-se os moldes franceses. Com efeito, Bittencourt (1993, p. 203) lembra que "parte significativa dos intelectuais e educadores brasileiros encarregados da elaboração e organização do ensino de História optou pelos franceses, adaptando programas e traduzindo livros didáticos". Até mesmo as reformas no ensino que surgiram se preocuparam em monitorar as transformações da conjuntura francesa. A autora destaca, ainda, que os materiais obtidos pelo Colégio Pedro II serviam de modelo para os demais cursos das províncias do Brasil, com o intuito de combater o socialismo emergente. Assim, tem-se que

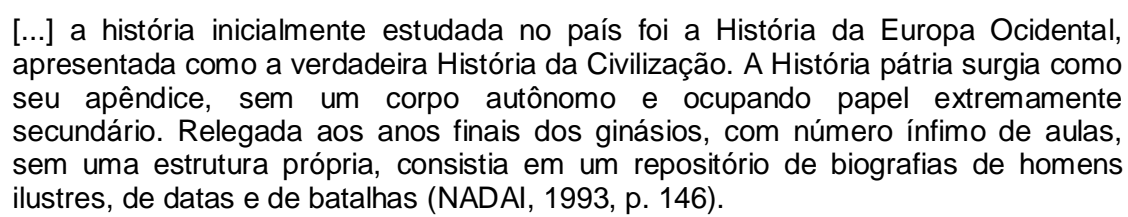

Mais tarde, a influência de intelectuais nos estudos históricos relativos à História do Brasil foi, com o passar dos anos, modificando as convicções sobre o ensino, embora as metodologias de aprendizagem tenham permanecido tradicionais por muito tempo. Reis (2007), na obra As Identidades do Brasil de Varnhagen a FHC, apresenta muito bem esse processo de mudanças nas concepções historiográficas, fundamental para a compreensão da constituição do país. 
Varnhagen, considerado o "Heródoto brasileiro"3 foi pioneiro nos escritos sobre a identidade nacional brasileira. Sua intenção, solicitada e mantida com os recursos e a proteção do imperador, era despertar, na jovem nação miscigenada, o sentimento de pertença ao "Brasil português". Em sucessão, outros pensadores surgiram, como Capistrano de Abreu, Gilberto Freyre e Sérgio Buarque de Holanda, que, com críticas ao que se tinha produzido até o momento e seguindo as concepções emergentes de sua época, apresentaram novos olhares à História do país. As produções desses estudiosos contribuíram significativamente para a compreensão da História do Brasil e do seu povo, sendo utilizadas frequentemente nas instituições de ensino, como mostra o trecho que segue:

\begin{abstract}
Joaquim Manuel de Macedo, professor de História do Colégio Pedro II, autor de obras de História e Geografia, optou por uma cronologia baseada "na História Geral do Brasil do S. Varnhagen, que especialmente em verificação de fatos e datas é a melhor de quantas até hoje estudado". Macedo dividiu o trabalho em trinta e nove lições, fixadas por datas, sendo as três últimas compostas como índice cronológico. Toda a obra foi composta de maneira a fazer o aluno fixar a cronologia, apresentando, ao final de cada lição, "quadros sinóticos" com eventos considerados como fundamentais e suas respectivas datas (BITTENCOURT, 1993, p. 210).
\end{abstract}

Na primeira metade do século $X X$, os movimentos da Escola Nova, que visavam uma renovação no ensino, ganharam força na Europa e alcançaram o Brasil, promovendo algumas reflexões importantes. O escolanovismo pautava-se na ideia de que a educação era o caminho para o desenvolvimento de uma sociedade democrática, capaz de respeitar e compreender a diversidade e as especificidades do sujeito. Nesse sentido, a educação teria de se centrar no indivíduo, a fim de torná-lo um cidadão democrático e apto para se inserir na sociedade. O movimento também entendia que, para o processo de ensino e aprendizagem, era necessário inovar com metodologias e incentivo à pesquisa, estimulando a criticidade ante as mais variadas questões.

Nadai (1993) entende que as medidas em relação à inovação do ensino de História deram-se em 1934, com o estabelecimento de cursos inéditos dedicados à formação docente. O primeiro deles foi oferecido pela instituição da Faculdade de Filosofia, Ciências e Letras, em São Paulo. Outros ocorreram, também, na Universidade do Brasil no Rio de Janeiro. É, de fato, perceptível a importância da preocupação com o processo formativo docente. Garcia (1999, p. 26) afirma que é através do processo formativo que os professores "adquirem ou melhoram seus conhecimentos, competências e disposições que Ihes permitem intervir profissionalmente no desenvolvimento do seu ensino, do currículo e da escola".

3 Varnhagen ficou conhecido como "Heródoto brasileiro" por iniciar a pesquisa metódica em arquivos estrangeiros, encontrando e produzindo diversos documentos relativos ao Brasil. 
É interessante, porém, lembrar que, neste período, no Brasil, o ensino de História não apresentou avanços significativos quanto à metodologia e à didática. Estas, ainda ancoradas no positivismo, continuavam focando em cronologias e estimulavam a memorização de datas e nomes de personagens importantes relacionados à sua heroicidade, não se importando com o coletivo. As noções de tempo histórico eram, pois, confundidas com a cronologia, não permitindo rupturas nesse sentido. Considerando essa situação, Nadai (1993, p. 150) afirma que

O resultante dessa abordagem reproduzida há décadas nos programas de História foi a construção de algumas abstrações, cujo objetivo tem sido realçar, mais uma vez, um país irreal, mascarando as desigualdades sociais, a dominação oligárquica e a ausência de democracia racial.

Este cenário despertou inquietação em alguns estudiosos, que logo se empenharam em repensar essas metodologias. A École des Annales ${ }^{4}$ apresentava, através de seu conteúdo programático, essa desejada revolução no ensino, pois se preocupava com o alargamento das fontes de pesquisa e com a organização das sociedades, reconhecia a importância dos estudos do cotidiano e atentava para a interdisciplinaridade na busca de romper com a estrutura positivista e com o modo de estudo reducionista marxista. A influência dessa Escola foi fundamental para estruturar novos olhares sobre o ensino e a pesquisa histórica no Brasil, através de seus programas, estabelecidos pelas gerações que compuseram o movimento.

Uma importante ação nesse sentido foi a série de convenções, feitas a partir da década de 60, entre o Ministério da Educação (MEC) e a United States Agency for International Development (Usaid), fortalecendo a relação política entre Brasil e Estados Unidos que há tempos vinha florescendo. A Reforma Universitária, instituída através da Lei 5540 de novembro de 1968, é um exemplo do resultado desses convênios, conhecidos como "Acordos MEC-Usaid", que apresentam, em sua estrutura, as intenções estabelecidas pelos estudiosos americanos (PINA, 2011).

Quanto a essa colaboração, seu propósito era o de implementar o modelo americano na educação brasileira. Para tanto, as universidades serviam como agentes articuladores das propostas de aperfeiçoamento, voltadas para o progresso do país e para o aprimoramento da cultura no ensino superior, e articuladas por docentes instruídos para este fim. Com isso, buscava-se estabelecer uma concepção nova de formação que abarcasse o tenro projeto que envolvia o país e a política americana.

4 Conforme Bourdé e Martin (1983, p. 119), é a tendência da historiografia francesa apoiada em narrativas com concepção no tempo de longa duração. Deriva a atenção da vida política para atividade econômica, a organização social e a psicologia coletiva; esforça-se por aproximar a História de outras Ciências Humanas. 


\section{O Curso de História na UCS: Implantação e Desenvolvimento}

$\mathrm{Na}$ cidade de Caxias do Sul/RS/Brasil, entre os anos 1950 e 1960, implantaram-se os primeiros cursos superiores isolados, como a Faculdade de Ciências Econômicas; Filosofia, Ciências e Letras; a Faculdade de Direito; a Faculdade de Enfermagem e a Faculdade de Belas Artes. Estas deram, então, origem à Universidade de Caxias do Sul, no ano de 1967. Xerri (2012) examina, em sua tese de Doutorado, a constituição da UCS, refletindo sobre "o pensar e o construir da Universidade na Serra Gaúcha”. Nesse sentido, a autora diz que

[...] é importante evocar a criação da universidade numa região interiorana do RS, sob a ação de mantenedoras representativas do poder público municipal, de ordem religiosa católica, da Mitra Diocesana e do Grupo Hospital Nossa Senhora de Fátima; entrelaçando com a paroquialização na medida em que estas micro-células compõem um organismo maior, a UCS (XERRI, 2012, p. 89).

A pesquisadora evidencia a importante influência da Igreja Católica na fundação da Faculdade de Filosofia de Caxias do Sul, que interessa especialmente neste trabalho, e a posterior constituição da UCS, com a mediação de Dom Benedito Zorzi, da Mitra Diocesana. A Faculdade de Filosofia abarcava os cursos de Filosofia, Pedagogia e História que, em 1960, iniciaram seus trabalhos e, no ano seguinte, também o curso de Letras. Os propósitos da Faculdade consistiam em:

a) Ministrar a seus alunos aprimorados conhecimentos filosóficos, científicos e literários; b) Formar professores para o curso secundário, normal e superior; d) Promover e incentivar a prática da pesquisa pessoal, conforme aptidões individuais dos alunos; e) Contribuir para a mais ampla difusão da cultura nacional, nos programas oficiais de ensino e norteada pelos princípios sadios da doutrina católica (XERRI, 2012, p. 143).

Para que se compreendam as concepções de ensino vigentes na época da fundação da Faculdade e diretamente relacionadas ao que hoje se conhece como Curso de Licenciatura em História, é necessário analisar brevemente como se deu a constituição da Faculdade e a sua relação com o Estado, dentro do contexto social, político e econômico do período. Para isso é essencial a pesquisa realizada no Centro de Documentação da Universidade de Caxias do Sul - CEDOC/UCS 5 que, por meio de sua equipe, forneceu o apoio necessário para a realização deste trabalho.

A Faculdade de Filosofia, Ciências e Letras foi fundada em 8 de julho de 1959 e teve sua instalação efetiva em $1^{\circ}$ de março de 1960. A autorização para seu funcionamento deuse por meio do Decreto no 47.668 de 25 de janeiro de 1960. O referido Decreto permitiu o

5 O CEDOC/UCS integra o IMHC, tendo como finalidade: "Preservar o acervo histórico documental da Instituição, de suas atividades acadêmicas, bem como da cultura regional e outros considerados de relevante importância Histórica, disponibilizando-o como suporte informacional no fomento à pesquisa do conhecimento". Dessa forma, atua como um laboratório de aprendizagem dos alunos, dos professores e da comunidade em geral, objetivando a familiarização com o cotidiano da pesquisa documental. Disponível em: https://www.ucs.br/site/instituto-memoria-historica-e-cultural/centro-dedocumentacao/. Acesso em: 20 set. 2018. 
funcionamento dos cursos de Filosofia, Letras Neolatinas, Geografia, História e Pedagogia, mantidos pela Mitra Diocesana. Nesse período, representava a Mitra Diocesana Dom Benedito Zorzi e, em caso de sua ausência, o Vigário Geral Dom Frei Cândido Maria. Inicialmente, a Faculdade funcionava no edifício da Escola Normal São José e, em 1962, mudou-se para as novas instalações, projetadas para a realização das atividades com maior eficiência. Conforme a documentação consultada, o regimento que trata da sua organização didática e administrativa está em conformidade com a LDB.

Chamam a atenção alguns papéis referentes à realização de visitas e viagens de estudo de 1963. Entre eles, encontra-se um documento, emitido em 17 de abril de 1963, pelo Padre Hilário que envia um ofício para a Faculdade de Filosofia, Ciências e Letras, informando que alguns alunos concluintes projetavam uma viagem aos Estados Unidos. Com ele, também solicitava que a direção da Faculdade atentasse para a providência quanto ao pedido de estada gratuita e locomoção de, provavelmente, 16 pessoas. O padre esclarece que a devida solicitação foi realizada junto ao Consulado dos Estados Unidos, na cidade de Porto Alegre, que a remeteu à Embaixada no Rio de Janeiro. Logo, pede que a direção realize um telefonema a "Dom Helder"6, para que o processo seja despachado imediatamente de modo favorável. Nota-se, nisso, as intenções em estabelecer relações com os Estados Unidos, de modo a acrescentar conhecimento no processo de ensino e aprendizagem.

É possível perceber, também, mudanças singelas, mas significativas, nos documentos que tratam da "organização e funcionamento da Faculdade de Filosofia, Ciências e Letras", que, a partir de 1967, passa a se chamar Faculdade de Filosofia, Ciências e Letras da Universidade de Caxias do Sul, e a ser mantida pela Associação da Universidade de Caxias do Sul, cujo reitor era Virvi Ramos.

Em abril de 1968, o então reitor faz algumas solicitações ao diretor da Faculdade, Paulo Zugno, com o objetivo de cumprir o planejamento do novo sistema de estrutura da Universidade, nos termos dos Decretos-lei n 53/66 e no 252/67, que apresentavam uma série de mudanças que afetariam o sistema universitário brasileiro. Entre seus pedidos, destacava-se o levantamento de todas as disciplinas de todos os cursos, para determinar o exato conteúdo, com vista a sua redistribuição, como previa o art. $6^{\circ}$ do Decreto-lei 53/66: "o desdobramento, a fusão e a extinção de unidades existentes em virtude da presente lei, bem como a redistribuição, transformação ou extinção dos cargos a elas distribuídos, serão declarados por decreto".

6 Assistente-geral da Ação Católica Brasileira, trabalhou pela criação da Conferência Nacional dos Bispos do Brasil (CNBB) sendo o secretário-geral até 1964, quando foi nomeado Arcebispo de Olinda e Recife. 
No mesmo ano, o então diretor Paulo Zugno solicitou, por meio do Ofício no 384, que fosse submetido ao Conselho Universitário da Universidade de Caxias do Sul, o pedido de autorização para funcionamento, a partir do ano de 1969 - que seria o próximo ano letivo -, dos seguintes cursos: Letras - Francês ou Inglês (primeiro ciclo), Estudos Sociais (primeiro ciclo) e Ciências Sociais. Diante disso, em fevereiro de 1969, é lançado o edital para inscrições ao concurso de vestibular para ingresso nos cursos de Licenciatura em Ciências, Ciências Sociais, Estudos Sociais, Geografia, História, Matemática, Letras-Português, Letras-Francês, Letras-Inglês e Filosofia.

No edital para o vestibular disponibilizado em junho seguinte, são novamente oferecidas vagas para os cursos de Licenciatura em Estudos Sociais, Licenciatura em História, Geografia e para os demais cursos. Diante disso, percebe-se a instituição de ensino adequando-se aos processos da Reforma Universitária e entende-se que muito dessa conjuntura permanece nas estruturas até os dias de hoje.

A nível nacional, durante esse período, a disciplina de Estudos Sociais vinha sendo implementada com caráter experimental em algumas escolas, mas, a partir de 10 de março de 1967, a sua adesão tomou caráter obrigatório no ensino básico e também nas instituições de Ensino Superior. Os Estudos Sociais vinham em substituição às disciplinas de História e Geografia e tinham o intuito de despertar civismo por meio do ensino. Garcia e Schmidt (2001, p. 4) afirmam que:

\footnotetext{
[...] de forma geral, nas décadas de 70 e 80 , as escolas desse nível de ensino desenvolviam conteúdos de Estudos Sociais, contemplando alguns aspectos do conhecimento histórico e geográfico, tomando como modelo curricular uma forma de organização em círculos concêntricos: o ensino deveria ser iniciado pelo mais próximo - a comunidade, o bairro - para depois incluir os estudos sobre a cidade, o país, o mundo.
}

Ainda sobre a questão da obrigatoriedade, a instauração da Doutrina do Núcleo Comum $^{7}$ pensada pelo Conselheiro Valnir Chagas, membro do Conselho Federal de Educação a partir de 1962, e docente de História da Educação na Universidade de Brasília, teve fundamental importância dentro dos grupos envolvidos na constituição das Leis no 5.540/68 e no 5.692/71, que fixam, respectivamente, normas de organização do Ensino Superior e sua articulação com a escola média e as diretrizes e bases para o ensino de $1^{\circ} \mathrm{e}$ $2^{\circ}$ graus. Nascimento e Santos (2015) relatam que, além de influenciado pelas ideias de John Dewey, da Escola Nova, o conselheiro também se apropriava das teorias de Piaget para a formulação de seus conceitos.

7 A Lei 5.692, por determinação, separou os conteúdos em núcleo comum (obrigatório em âmbito nacional) e parte diversificada (para atender peculiaridades locais) R. bras. Est. pedag., Brasília, v.74, n. 177, p.387, maio/ago. 1993. 
A Lei n. 5.692/71, chamada por Chagas de "divisão tríplice", estabeleceu, além da disciplina de Estudos Sociais (História, Geografia e Organização Social e Política do Brasil OSPB), também as disciplinas de Comunicação e Expressão (Língua Portuguesa e Língua Estrangeira) e Ciências (Matemática e Ciências Físicas e Biológicas). Nascimento e Santos (2015) afirmam que ela tinha o objetivo de diferenciar currículo de matéria. Nesse sentido, a construção da proposta de ensino ficaria ao encargo das escolas. Acrescentam, ainda, que, de certo modo, a proposta da Lei apresentava certa plasticidade, já que as instituições de ensino tinham a responsabilidade da construção dos conteúdos que comporiam as disciplinas constituidoras das matérias do núcleo comum. Logo, percebe-se a configuração própria que o currículo apresentava. Quanto à análise dos aparatos da Lei, é possível perceber que o processo de ensino e aprendizagem "não se restringia apenas à aquisição de conhecimentos, mas promovia um processo que englobava habilidades, atitudes e criatividade" (NASCIMENTO; SANTOS, 2015, p. 169).

São notáveis os impactos dos Acordos MEC-Usaid no sistema de ensino brasileiro através da implementação de um projeto norte-americano na educação brasileira. É nesse contexto que uma diversidade de materiais relacionados aos Estudos Sociais chegou ao Brasil, como afirmam Nascimento e Santos (2015). Dentre eles, destacam-se os livros Estudos Sociais para crianças numa democracia (MICHAELIS, 1963) e Ensino de estudos sociais na escola primária (PRESTON, 1964). Ambos materiais são voltados para a formação de professores e o primeiro, que aqui interessa de modo particular, será analisado mais adiante.

Em específico para o contexto enfocado neste trabalho, vale dizer que a análise dos conteúdos das Propostas Curriculares de disciplinas de Didática, relacionadas à Formação Docente do Curso de História da Universidade de Caxias do Sul, observando as prescrições didáticas para o ensino de História, se torna essencial para perceber como o processo de formação de professores se desenvolveu na Instituição nos anos 1960. Entende-se que as concepções que então se estabeleceram e os reflexos dessa conjuntura, de algum modo, repercutiram no ambiente escolar, principal meio de construção de saberes capazes de desenvolver a criticidade e autonomia dos indivíduos.

Ivor Goodson (1995) considera que um dos problemas relacionados a questões de currículo define-se por este encontrar-se "multifacetado, construído, negociado, renegociado em vários níveis e campos" (GOODSON, 1995, p. 67). Assim, o desafio a que se propõe esta pesquisa torna-se significativo, visto o contexto político, social e econômico do recorte temporal do estudo: buscar compreender esses impactos na constituição docente é essencial no sentido de averiguar os ideais americanos na formação cidadã brasileira. 
Goodson (1995) afirma que entender como o currículo é criado, é uma situação que teria de propiciar "mapas ilustrativos" dos alicerces e intentos que permeiam a prática contemporânea. Para o autor, currículo pode ser definido como

[...] o curso aparente ou oficial de estudos, caracteristicamente constituído em nossa era por uma série de documentos que cobrem variados assuntos e diversos níveis, junto com a formulação de tudo - "metas e objetivos", conjuntos e roteiros - que, por assim dizer, constitui as normas, regulamentos e princípios que orientam o que deve ser lecionado (GOODSON, 1995, p. 117).

O autor defende a construção social do currículo e, nesse sentido, considera-o como uma "tradição inventada". Para sustentar sua teoria, se apropria do pensamento de Hobsbawm, quando este se refere à Invenção das Tradições $^{8}$

Saviani (2016), por sua vez, apresenta o currículo como o grupamento de práticas nucleares que se desenvolvem em uma instituição de ensino, validadas ou não. No que tange aos conteúdos que compõem o currículo, o autor acrescenta que as demandas sociais é que movem essa construção em todas as suas modalidades e níveis. Nesse sentido, Apple (1982, p. 97) entende que "os interesses sociais e econômicos que serviam como base para a atuação dos mais influentes especialistas em currículo não eram neutros nem fortuitos", pois, ao estabelecer acordos com bases políticas e econômicas, tendiam ao estabelecimento de desigualdades e controle sociais. Assim, o autor acredita que o currículo é ideologicamente construído.

Esse entendimento foi de suma importância para pensar as mudanças que ocorreram nas Propostas Curriculares do Curso de História da Faculdade de Filosofia, Ciências e Letras da Universidade de Caxias do Sul na década de 1960. Quanto ao currículo mínimo inicial, o Curso de História apresentava: História Antiga, Antropologia, Arqueologia e PréHistória, História do Brasil, História da América, Etnologia, História Medieval, Etnografia do Brasil, História Moderna, História Contemporânea e História Regional. Quanto ao currículo complementar, tem-se: Introdução aos Estudos Históricos, Fundamentos Geográficos e as Relações Humanas, História da Igreja e História da Arte. Já entre as disciplinas formativas obrigatórias do curso de História concomitante com os demais cursos, figura: Iniciação Filosófica, Teologia Dogmática, Sociologia, Doutrina Social da Igreja, Psicologia Educacional, Teologia Moral, Filosofia da Educação, Didática Geral e Didática Especial.

Evidencia-se um ensino baseado fortemente em concepções religiosas. Na disciplina de Teologia Dogmática, por exemplo, tratavam-se alguns temas, como: Os caminhos de fé: a vida de Jesus Cristo; A essência do homem Cristão e os meios para alcançar na nossa

8 Tradição inventada significa um conjunto de práticas e ritos: práticas normalmente regidas por normas expressas ou tacitamente aceitas, e ritos - de natureza simbólica - que procuram fazer circular certos valores e normas de comportamento mediante repetição, que implica automaticamente continuidade com o passado. De fato, onde é possível, o que tais práticas e ritos buscam é estabelecer a continuidade com o passado histórico apropriado (HOBSBAWM; RANGER, 1984, p. 1). 
vida: os sacramentos, o batismo, a eucaristia e o matrimônio; O Cristão perante os problemas atuais: o evolucionismo, o monogenismo, o espiritismo, o problema social (o comunismo e o capitalismo). Com isso, percebe-se que por todo o período analisado, essas concepções de ensino mantiveram-se efetivamente.

De fato, parece que a educação na Faculdade de Filosofia Ciências e Letras ainda se dava de um modo bastante positivista e tradicional, que não pretendia, de certo modo, desvencilhar-se da História Sagrada. Ao analisar algumas provas realizadas por alunos do Curso de História percebe-se, ainda e corroborando com ideais positivistas, que, mediante correção do professor, questionava-se com veemência a falta de informações sobre datas nas formulações de respostas dos alunos. Em um exemplo de prova aplicada, o docente solicitava respostas objetivas sobre: 1) Dia, mês e ano do efetivo início da viagem de Pedro Álvares Cabral rumo as Índias e 2) Duas realizações maiores de Maurício de Nassau no Brasil. Esses dados vêm a fortalecer o pensamento de que as concepções de ensino nas universidades nada apresentavam de mudanças significativas nesse sentido.

\section{Material de Apoio: Reflexões sobre um Manual de Formação de Professores}

Quanto à análise do manual Estudos Sociais para crianças numa democracia, dentro do espaço possível, buscar-se-á refletir sobre as prescrições aos professores em relação à compreensão sobre as dimensões de tempo, espaço e linguagem e comunicação, pois, sem essas noções, não há compreensão dos fatos históricos e, portanto, entende-se que o desenvolvimento da consciência histórica fica prejudicado.

O livro apresenta prescrições aos professores que desejam "melhorar a educação social das crianças" e a ideia central nele defendida é a de que "os valores e o comportamento democráticos devem impregnar todas as fases do programa de estudos sociais". O material, que sugere a manipulação da capacidade crítica dos envolvidos no processo de educação, é um exemplo de implantação do modelo de ensino norteamericano, e esses reflexos são percebidos ainda hoje nas instituições e também na sociedade. Seu intuito era a "democratização" do Ensino Superior, pois, modernizando a economia, o principal modo de ascensão social se dava por meio da escolarização (SAVIANI, 1996).

Logo se compreende o pensamento americano nas prescrições descritas e pode-se desenhar com alguma especificidade o modelo de professor que provavelmente foi formado 
a partir do texto. Desse modo, é possível perceber as concepções de ensino delineadas nesse contexto e, então, refletir sobre os reflexos deste padrão de educação na sociedade.

Circe Bittencourt (2008), por meio de sua obra Ensino de História: fundamentos e métodos, analisa o modo como acontecem as aprendizagens no processo de ensino de História, esclarecendo como o conhecimento histórico se desenvolveria de maneira eficaz. A partir dessas perspectivas, é possível encarar a análise da obra com um novo olhar para o processo de ensino e aprendizagem.

Para a leitura do texto, também serve de apoio a tese "Propostas curriculares para o ensino de estudos sociais: circulação e apropriação de representações de ensino de história e de aperfeiçoamento de professores (Espírito Santo, 1956-1976)", realizada por França (2013), que ajuda a pensar o contexto de produção do material e que incentivou o desenvolvimento desta pesquisa. No capítulo intitulado "Representações de intelectuais: ensino de Estudos Sociais em movimento de histórias conectadas”, o autor dedica um espaço para tratar de John Michaelis e seu Estudos Sociais para crianças numa democracia. Ao longo do texto, o autor analisa produções didáticas de autores brasileiros e estadunidenses que tiveram circulação na cultura escolar e foram utilizados por docentes durante anos. Nesse sentido, França (2013, p. 30) busca identificar "as permanências e distinções entre as representações de ensino de Estudos Sociais e aperfeiçoamento de professores".

Segundo o autor, o conhecimento produzido nos Estados Unidos motiva a cultura escolar através das publicações e traduções de manuais, livros, compêndios, entre outros materiais metodológicos que, de certo modo, disseminaram as representações em relação aos Estudos Sociais. Conforme o autor, para John Michaelis, o trabalho com Estudos Sociais teria de ser criado "como uma referência especial às finalidades da educação na democracia americana e aos objetivos globais da educação: autorrealização, o foco nas relações humanas, a eficiência econômica e a responsabilidade cívica" (FRANÇA, 2013, p. 115). França refere, ainda, que, para o intelectual estadunidense, a noção de democracia é assimilada como uma forma eficaz de viver sendo fundamental que

[...] o programa de Estudos Sociais, em todas as fases de aprendizagem,
contemplasse os valores democráticos, oportunizando aos alunos vivê-los no
cotidiano escolar e em todas as relações sociais mútuas. Aí encontramos a principal
responsabilidade do professor de Estudos Sociais: elaborar planos de aprendizagem
para desenvolver o comportamento democrático, por meio das experiências vitais da
aprendizagem encontradas nas situações vitais em todas as fases da vida cotidiana
das crianças (FRANÇA, 2013, p. 115).

Diante disso, é perceptível que Michaelis (1970) designou o seu trabalho para os docentes que ansiavam aperfeiçoar a educação social dos alunos e objetivava convencê-los 
de que o pensamento e a prática democrática tinham o dever de estarem presentes em todos os estágios do ensino de Estudos Sociais. França (2013) traz à tona o relacionamento entre os escritos do intelectual e as suas próprias experiências e vivências. Michaelis foi

[...] professor, intelectual e um líder no contexto das relações internacionais. Ou seja,
a sua escrita foi extremamente influenciada pela sua atuação na direção da
delegaçãa dos Estados Unidos, na Organização das Nações Unidas para a
Educação, Ciência e a Cultura (UNESCO), no Departamento dos Estados Unidos,
especificamente no Líbano, nas Filipinas, na Birmânia e no Equador, a partir de
1951. Diante disso, observamos o caráter multicultural da sua produção bibliográfica,
bem como a preocupação com a interlocução com os educadores dos países da
América, Ásia e África (FRANÇA, 2013, p. 116).

O autor acrescenta que Michaelis, no contexto da Guerra Fria, busca delinear e representar o ideal de democracia americana, além de divulgar o estilo de vida americano, ou American Way of Life, em um momento propício para os Estados Unidos. Chama a atenção que, segundo o autor, nos escritos do intelectual estadunidense, é possível perceber a sua crítica em relação ao modelo tradicional de ensino baseado na memorização dos conteúdos, fortemente presente na educação brasileira neste período.

França (2013) menciona, ainda, em seu trabalho, o empenho de John Michaelis em facilitar a aprendizagem dos conceitos de tempo e espaço e promover o desenvolvimento das relações sociais por meio da interação da criança com o ambiente familiar e escolar. Nesse sentido, propõe-se, aqui, analisar os modos como essas noções são apresentadas no texto, as prescrições para os professores e as metodologias estabelecidas para a apreensão dos conceitos fundamentais para o conhecimento histórico e a compreensão do passado.

Antes de adentrar aos objetivos do manual, é importante compreender sua mensagem paratextual. Genette (2009) indica que os paratextos são o limiar entre o dentro e o fora; a zona de transição, entre o texto e o extratexto, caracterizando-se, empiricamente, como um conjunto heteróclito de práticas e de discursos. Os elementos podem ser verbais ou não, como, por exemplo, nome do autor, título, ilustrações, e prefácio, que, juntamente com o texto, constitui o objeto livro.

O exemplar em análise tem sua impressão em 1970, com tradução de Leonel Vallandro. É a $4^{\text {a }}$ impressão da $2^{\text {a }}$ edição publicada pela Editora Globo, que nasceu da Livraria do Globo, em dezembro de 1883. Torresini (1998) registra o endereço: Rua da Praia, centro de Porto Alegre. Nos anos 1940, a editora apresenta obras ligadas às ciências humanas, dicionários e gramáticas.

O exemplar, com 555 páginas, apresenta lombada quadrada, com o título Estudos Sociais para crianças numa democracia dividido em duas linhas; sua capa e contracapa têm três cores: fundo azul, e preto e branco utilizados basicamente em algumas tipografias, 
como título, nome do autor e nome da editora. A capa apresenta um elemento gráfico, que é uma linha, na cor branca. A contracapa apresenta, ao centro, sobre o fundo azul, imagem com fachada traseira da Livraria do Globo em Porto Alegre. A simplicidade do projeto gráfico pode ter justificativa na crise financeira enfrentada pela Editora na década de 1970, que, procurando baratear custos, adota alternativas para a publicação de materiais com apelo pedagógico. Uma das alternativas foi o uso de apenas duas cores para impressão (FACIN, 2008 apud RAMIL, 2012). Tal situação pode indicar, também, a pouca qualidade da impressão em offset, o que, entretanto, causa estranhamento, sendo uma publicação ilustrada e de cunho pedagógico.

O espaço da orelha, na capa e também na contracapa, é ocupado com um texto do próprio Michaelis apresentando sua obra, seus objetivos e a intenção maior de que o guia facilitasse, ao professor, a tarefa de transformar Ciências Sociais em Estudos Sociais.

No manual, o tópico "Contribuições dos Estudos Sociais para os objetivos da Educação" apresenta as funções e os objetivos dos Estudos Sociais, que necessitam atender e estar de acordo com os objetivos da educação na democracia americana. Nesse sentido, o autor justifica que os Estudos Sociais contribuem de modo específico "para a auto-realização, as relações humanas, a eficiência econômica e a responsabilidade cívica" (MICHAELIS, 1970, p. 10). Acrescenta, ainda, que os Estudos Sociais oferecem muitos meios para desenvolver e fortalecer as relações sociais pela linguagem, pela cooperação mútua e pela resolução de problemas em conjunto.

A ênfase ao estudo e o aprimoramento das relações humanas, seja na família ou na comunidade, devem ser estimulados, pelo professor, na desenvoltura de valores democráticos. Cabe ao docente "despertar a apreciação do lar, dos ideais familiares e do papel de cada membro da família em todos os níveis de ensino, enquanto os grupos são estudados dentro e fora dele" (MICHAELIS, 1970, p. 11).

Conforme o autor, o aluno deverá evoluir em seu aprendizado, em suas aptidões, em cognição, em percepção e em conduta, que se inserem no que ele chama de linhas de comportamento. Michaelis entende que, através dos Estudos Sociais, é possível fazer com que a criança: se torne uma pessoa democrática (enquanto agente guiado por valores democráticos); desenvolva certos tipos de comportamento que sejam convenientes com os valores democráticos; reconheça a importância do trabalho em conjunto, mostrando o respeito às diferentes opiniões e entendendo a importância do desenvolvimento do pensar através do espírito crítico e construtivo com intuito de resolver problemas percebidos em sociedade; compreenda que, através do aprendizado dos Estudos Sociais, é possível ter 
apreço com os outros e respeitar as semelhanças e diferenças entre culturas, reconhecendo a importância das relações sem levar em conta cor, raça ou classe.

Michaelis (1970) evidencia que é possível, também, apropriar-se de conhecimentos, conceitos e compreensões construtivas em relação às funções sociais básicas do ser humano,

\begin{abstract}
[...] tais como a produção de utilidades de serviços, os transportes e comunicações, a conservação dos recursos naturais, a expressão estética e religiosa, a educação, a recreação e o governo, o impacto dos progressos da ciência e da educação sobre o sistema de vida, o efeito dos valores morais e espirituais sobre o comportamento humano, as maneiras de melhorar a vida de família, a vida em comunidade e o bemestar nacional e internacional, e a interdependência cada vez maior que caracteriza a vida moderna (MICHAELIS, 1970, p. 15).
\end{abstract}

Diante desses apontamentos, é possível perceber, ademais, que o manual expressa ser através dos Estudos Sociais que a alteridade pode ser desenvolvida: ela acontece no momento em que alguém se coloca no lugar do outro, com o intuito de aprender e sentir suas necessidades e problemas; tal comportamento leva ao indivíduo agir com coragem e integridade integrados, a participar dos processos democráticos e a praticar seus ideais.

Michaelis (1970, p. 15) acrescenta que, para alcançar esses objetivos, "é necessário que os valores democráticos vitalizem todas as fases do programa", uma vez que o comportamento democrático necessita ser desenvolvido de modo prático e concreto. Assim, "os valores e o comportamento democrático apreendidos nos Estudos Sociais podem ser utilizados e transportados para situações que venham a surgir no lar na escola e na comunidade" (MICHAELIS, 1970, p. 16).

Esses pressupostos, quando relacionados com o ensino de Estudos Sociais, trazem a intencionalidade de romper com os paradigmas da educação tradicional que permeava o processo de ensino e aprendizagem do período. Notam-se, claramente, as intenções em promover a interação entre os indivíduos, trabalhando e fortalecendo as relações sociais por meio da interculturalidade. As noções de tempo e espaço permeiam esse enumerado de comportamentos e objetivos traçados, que o autor considera como passos a serem seguidos, como degraus a serem alcançados um após o outro.

A criticidade, mesmo que discreta, ante os problemas sociais, é percebida entre as intenções dessa visão americana de Estudos Sociais. O desenvolvimento de habilidades relacionadas ao aprendizado, em consonância com as múltiplas linguagens no ensino, é estimulado no manual, já que este apresenta prescrições, ao professor, para o trabalho com as tecnologias da época. Com efeito, na educação, o uso dessas tecnologias é de fundamental importância, pois 
[...] a presença em sala de aula de formas de expressão das múltiplas linguagens, como um texto literário, dentre eles a poesia, uma fotografia aérea ou um filme deve atender àquilo que é próprio do ensino de Geografia. A leitura e interpretação dessas formas de expressão das linguagens nas nossas aulas devem estar a serviço do desenvolvimento do olhar geográfico, da interpretação geográfica do mundo que nos cerca, e não o inverso. Portanto, a utilização de linguagens pelo professor, pela professora de Geografia deve possibilitar uma ressignificação dos conhecimentos com os quais a criança e o jovem, chega às suas aulas. Nesse processo, o chamado senso comum, o conhecimento menos elaborado com o qual os alunos, estão comunicando sua visão de mundo, é confrontado com um saber mais elaborado. As linguagens e suas formas de expressão e, sobretudo, o conhecimento que elas carregam, encontram-se presentes nesse confronto ou contraposição (FILIZOLA, 2009, p. 88).

No capítulo IX do manual, existe uma gama de prescrições relacionadas ao uso de materiais audiovisuais, voltados ao desenvolvimento da aprendizagem por meio da manipulação de objetos e do acesso a filmes, imagens, gravações, entre outros métodos. Nesse sentido, Michaelis (1970, p. 246) entende que

[...] os conceitos e informações adquiridos pelo uso desses materiais conservam-se mais tempo na memória do que quando são apresentadas unicamente por meios verbais; são, além disso, aprendidos mais depressa e podem ser utilizados imediatamente em atividades correlatadas, com grande economia de tempo.

O autor acrescenta que utilizar-se desses métodos facilita o trabalho com conceitos e processos sobre os conteúdos de Estudos Sociais de modo significativo e concreto. No capítulo seguinte, o escritor apresenta os modos e as competências possíveis de serem atingidas com o uso eficiente de globos e mapas nos Estudos Sociais, haja vista o impacto dessas metodologias na aprendizagem e no desenvolvimento cognitivo dos alunos.

Michaelis disserta sobre a necessidade de praticar o comportamento democrático, de forma a consolidar seu conceito, indo além dos valores trabalhados em relação à democracia. O autor considera como "prova de fogo" a análise dos comportamentos das crianças e, portanto, afirma que o professor precisa ter sensibilidade para reconhecer esse comportamento democrático nas mais diversas situações para que possa planejar o modo eficiente, incentivando os passos para alcançar esse comportamento e avaliando o seu progresso.

É importante evidenciar que, para ele, dentro dos valores democráticos, devem-se inserir os seguintes tipos de comportamentos: a responsabilidade, interesse pelos outros, receptividade, faculdade criadora e a cooperação. Michaelis (1970) postula que, a cada fase do processo de ensino e aprendizagem, devem-se contemplar esses aspectos que se desenvolvem nas relações cotidianas do meio social em que a criança vive. Entre as prescrições para este fim, estão algumas ações a que o professor precisa atentar ao desenvolver seus planos de estudos, a saber: fazer, observar e estudar. Isto é, 
[...] em primeiro lugar cumpre planejar determinadas coisas para as crianças fazerem, já que é pela participação efetiva que se vive e se aprende o comportamento democrático, em segundo é preciso elaborar planos para que as crianças observem o comportamento democrático em ação, em terceiro faz-se mister que as crianças possam estudar e analisar o comportamento democrático tal como é retratado nos livros, filmes e outros materiais de ensino (MICHAELIS, 1970, p. 27).

Embora a intenção do autor seja boa, os modos de aprendizagem acabam homogeneizando os indivíduos, analisando as situações de maneira totalizante, não considerando as diferenças sociais e entendendo as famílias e comunidades como lugares de perfeita harmonia de reprodução de atitudes.

Ao trabalhar a sequência de unidades prescritas nos Estudos Sociais, percebe-se que ela se baseia nos modos de círculos concêntricos, pois parte de análises relacionadas ao ambiente adjacente à criança, se estendendo para o estudo da comunidade e, então, para o estudo dos povos distantes no espaço e no tempo. O intelectual traz composições curriculares de diferentes estados americanos, como Califórnia, Pensilvânia e Nova York, e de cidades como Denver e Cincinnati, destacando que unidades sobre lar e família são recomendadas para o primeiro grau, em quase todas as guias de currículo, estimulando a essência da linguagem e comunicação nas relações humanas.

Michaelis (1970) refere que muitos Estados possuem determinações específicas em relação à "educação cívica e ao ensino de história da Constituição, da obsenância de feriados especiais, do hasteamento e desfile da bandeira, do patriotismo e assuntos similares diretamente relacionados aos estudos sociais [sic]" (MICHAELIS, 1970, p. 55). O autor lembra, também, que tomadas as exigências dos Estados, existem, ainda, as regulamentações das Secretarias Estaduais e locais da Educação, como ampliação e complementação da legislação Estadual.

Porém, percebe-se que o autor possui, imbricado em seus interesses, os ideais positivistas, de modo a garantir o fortalecimento do nacionalismo. Ele orienta, ainda, que os professores tenham cuidado com as prescrições que podem ser obtidas "no código escolar, nos sumários de prescrições publicados pelas Secretarias de Educação, nos guias de currículo ou no registro escolar de matrícula e Frequência" (MICHAELIS, 1970, p. 56) e alerta que, se for percebido algum impasse que prejudique o desenvolvimento de um bom programa escolar, o professor deverá reportá-lo às autoridades competentes, a fim de notificar o ocorrido.

Quando propõe o estudo da comunidade, vemos o esforço de Michaelis em estimular o aprendizado dos alunos por meio de atividades práticas e interativas, que vão de encontro à visão tradicional de ensino bem presente no contexto educacional brasileiro. Nesse 
sentido, o professor teria o dever de planejar a exploração de informações em favor da constituição do conhecimento.

Em específico, o autor apresenta uma lista de verificações para o estudo da comunidade, são elas: visitas a locais (indústrias, museus etc.); pessoas fontes (visitantes especializados: grupos ou indivíduos); rádio e televisão (programas de viagens, peças históricas); publicações (jornais, bibliotecas, boletins da câmara de comércio); organizações beneficentes e de serviço à comunidade (Cruz Vermelha, Rotarianos etc.); planos de serviço (programas de auxílio, operações de limpeza); possíveis estudos de campo (habitação, segurança); recursos visuais (gravuras e fotos, peças autênticas); atualidades locais (campanhas, etc.); recursos da própria escola (coleções de materiais, professores que fizeram viagens); recursos recreativos da comunidade (parques, facilidades para acampamento); recursos populacionais (indivíduos, festas populares).

A partir dos resultados obtidos com essas fontes, o autor estimula aprofundar análise em relação às pesquisas mais abrangentes: História da comunidade; população; vida doméstica e familiar; Governo; vida organizada de grupo; comunicações e transportes; organizações públicas e privadas de beneficência; recursos naturais; saúde e segurança; oportunidades recreativas; consenvação; indústria e comércio; arte, música e literatura; oportunidades educacionais. Dentro dessas propostas de trabalho, em primeiro olhar, percebe-se, de modo claro, que o manual trata das questões relacionadas às noções de tempo, espaço e linguagem e comunicação, em meio às atividades acima prescritas, inteirando o aluno e o estimulando no desenvolvimento dessas concepções.

Por fim, nota-se, também, a importância de compreender o manual para além do conteúdo escrito, isto é, compreender sua materialidade e a comunicação possibilitada pelos elementos visuais. Deixa de ser apenas um recurso pedagógico e didático para formação de professores, para ser um discurso sobre um tempo.

Diante das questões e apontamentos deste trabalho, fica clara a influência americana que se instaurou na educação brasileira através da adoção de materiais didáticos como o manual Estudos Sociais para crianças numa democracia, de John Michaelis. Ela alcançou, de certo modo, a Universidade de Caxias do Sul, como evidenciado através da averiguação nos documentos relacionados ao que hoje se conhece como Curso de Licenciatura em História, salvaguardados no CEDOC/UCS, e que, no período analisado, compunha a Faculdade de Filosofia, Ciências e Letras da Universidade de Caxias do Sul.

No Brasil, questões voltadas para a história do ensino de História passaram a ser objeto de debates e interrogações por volta dos anos 1980, visto o momento de reformas curriculares nas quais se discutia a substituição dos Estudos Sociais pela História e 
Geografia. Vive-se, hoje, uma recente inovação neste campo de estudos, que apresenta diferentes abordagens, preocupando-se em revelar a natureza ideológica em que a manipulação infiltrada pelas instituições apresenta seus interesses próprios (BITTENCOURT, 2008).

Estar atento a essas transformações faz parte da construção do próprio conhecimento, uma vez que é imperativo refletir sobre as possibilidades de uma sociedade justa, autônoma, crítica, conhecedora de sua própria história, atuante e apta em construir sua jornada, com vistas à mudanças profundas nas estruturas sociais, políticas e econômicas da realidade em que está inserida. Em sociedade, pensamentos divagam, se cruzam e se contrapõem. O desconhecimento que gera a ignorância, que gera a insensatez, que gera o comodismo, é percebido com frequência e, então, cabe perguntar qual o papel da educação e sua importância para a formação do cidadão. Nesse contexto, inserem-se essas reflexões e se considera que "é pensando criticamente a prática de hoje ou de ontem que se pode melhorar a próxima prática" (FREIRE, 1996, p. 44).

\section{Referências}

APPLE, Michael Whitman. Ideologia e currículo. São Paulo: Editora Brasiliense, 1982.

BITTENCOURT, Circe Maria Fernandes. Ensino de História, fundamentos e métodos. São Paulo: Cortez, 2008.

BITTENCOURT, Circe Maria Fernandes. Os confrontos de uma disciplina escolar: da história sagrada à história profana. Revista Brasileira de História, São Paulo, v. 13, n. 25-26, p. 183-221, set./ago. 1993.

BOURDÉ, Guy; MARTIN, Hervé. As escolas históricas. Sintra: Publicações Europa-América, 1983.

FILIZOLA, Roberto. Didática da Geografia: proposições metodológicas e conteúdos entrelaçados com a avaliação. Curitiba: Base Editorial, 2009.

FRANÇA, Aldaíres Souto. Propostas curriculares para o ensino de Estudos Sociais: circulação e apropriação de representações de ensino de História e de aperfeiçoamento de professores (Espírito Santo, 1956 - 1976). 2013. 294 f. Tese (Doutorado em Educação) Universidade Federal do Espírito Santo, Vitória, 2013.

FREIRE, Paulo. Pedagogia da autonomia: saberes necessários à prática educativa. 31. ed. São Paulo: Paz e Terra, 1996.

GARCIA, Carlos Marcelo. Formação de professores: para uma mudança educativa. Porto: Editora Porto, 1999. 
GARCIA, Tânia Maria Figueiredo Braga; SCHMIDT, Maria Auxiliadora Moreira dos Santos. Discutindo o currículo "por dentro": contribuições da pesquisa etnográfica. Educar em Revista, Curitiba, n. 17, p. 139-149, 2001.

GENETTE, Gérard. Paratextos editoriais. Cotia: Ateliê Editorial, 2009.

GOODSON, Ivor Frederick. Currículo: teoria e história. 4. ed. Petrópolis: Vozes, 1995.

HOBSBAWM, Eric; RANGER, Terence. A invenção das tradições. Rio de Janeiro: Paz e Terra, 1984.

MICHAELIS, John Udell. Estudos Sociais pra crianças numa democracia. 2. ed. Porto Alegre: Editora Globo, 1970.

NADAI, Elza. O ensino de História no Brasil: trajetória e perspectiva. Revista Brasileira de História, São Paulo, v. 13, n. 25-26, p. 143-162, set./ago. 1993.

NASCIMENTO, Thiago Rodrigues; SANTOS, Beatriz Boclin Marques dos. O ensino de Estudos Sociais no Brasil: da intenção à obrigatoriedade (1930-1970). História e Perspectivas, Uberlândia, v. 28, n. 53, p. 145-178, jan./jun. 2015.

PINA, Fabiana. Acordos MEC-Usaid: ações e reações (1966-1968). 2011. 187 f. Dissertação (Mestrado em História) - Universidade Estadual Paulista, Assis, 2011.

RAMIL, Chris de Azevedo. Do projeto à produção gráfica da coleção didática Tapete Verde (Editora Globo, década de 1970). In: SEMINÁRIO DE PESQUISA EM EDUCAÇÃO DA REGIÃO SUL, 9., 2012, Caxias do Sul. Anais [...]. Caxias do Sul: Universidade de Caxias do Sul, 2012.

REIS, José Carlos. As identidades do Brasil: de Varnhagen a FHC. Rio de Janeiro: Editora FGV, 2007.

SAVIANI, Dermeval. Educação escolar, currículo e sociedade: o problema da Base Nacional Comum Curricular. Movimento: Revista de Educação, Rio de Janeiro, v. 3, n. 4, p. 54-84, 2016.

SAVIANI, Dermeval. Educação: do senso comum à consciência filosófica. 12. ed. Campinas: Autores Associados, 1996.

TORRESINI, Elizabeth Wendhausen Rochadel. Livros, leituras e leitores: a Editora Globo de Porto Alegre. Biblos, Rio Grande, v. 10, p. 173-178, 1998.

XERRI, Eliana Gasparini. Da Universidade da Serra à Universidade de Caxias do Sul/RS (1950 - 2002): o pensar e o construir da universidade na serra gaúcha. 2012. 312 f. Tese (Doutorado em Educação) - Pontifícia Universidade Católica do Rio Grande do Sul, Porto Alegre, 2012.

Recebido em 29/09/2018 Aprovado em 14/12/2018 